\title{
Uses of Monotherapy and Combination of Antihypertensive Drugs for Hypertensive Patients with Type-2 Diabetes
}

\author{
Dr. Md. Ahsan Habib*, Dr. Md. Aminul Hasan, Dr. Md. Rashadul Kabir, Dr. Md. Monwar Hossain
}

Assistant Professor, Department of Medicine, Shaheed Ziaur Rahman Medical College, Bogura, Bangladesh

DOI: $10.36347 /$ sjams.2020.v08i09.044

| Received: 01.09.2020 | Accepted: 08.09.2020 | Published: 30.09.2020

*Corresponding author: Dr. Md. Ahsan Habib

Abstract

Original Research Article

Background: Now a day association of diabetes in hypertensive patients is a very common issue. In fact, people with both diabetes and hypertension have approximately twice the risk of cardiovascular disease as nondiabetic people with hypertension. Besides monotherapy combinations of antihypertensive drugs are essential for many cases of hypertensive patients with type-2 diabetes. We have not enough data regarding the uses of monotherapy and combination of antihypertensive drugs for hypertensive patients with type-2 diabetes. Aim of the study: The aim of this study was to assess the uses of monotherapy and combination of antihypertensive drugs for hypertensive patients with type-2 diabetes. Methods: This was an observational cross sectional study and it was conducted in Dhaka Medical College Hospital and BIRDEM Hospital during the period from July2016 to June 2017. In total 140 diagnosed hypertensive patients with type 2diabetes mellitus attending to the Endocrine Departments of Dhaka Medical College Hospital and BIRDEM Hospital completed the full tenure of the study were finalized as the study population. After data analysis, results were find out according to the objectives, study result were presented in the form of tables, charts and description of the key findings according to need. The collected data were also be entered and analyzed using statistical software SPSS version 16. Result: In total $66(47.1 \%)$ patients of this study taken monotherapy and $74(52.9 \%)$ patients taken combination drugs. In this study, $73 \%, 23 \%$ and $4 \%$ patients taken double, triple and quadruple combination of antihypertensive drugs respectively. As monotherapy, ARBs, CCBs, ACEIs, Beta Blockers, and diuretics were used in 35\%, 23\%, 20\%, 16\% and 6\% patients respectively. In DMCH, ARB + Diuretics (8) and ARB + CCB (8) were most commonly used combinations. On the other hand, in BIRDEM, ARB + Diuretics (13) were most commonly used combinations and then B. Blocker + CCB (11) were most commonly used. Conclusion: Besides monotherapies combination therapies of antihypertensive drugs are used on a big ratio of hypertensive patients with type-2 diabetes. Moreover, there was higher use of B. blockers and less use of diuretics in our study. Still there is room for better control of hypertension and optimization of antihypertensive therapy. In spite of these data and published guidelines, inconsistencies exist towards treatment approach, because of which physicians sometimes have to individualize the therapy, based on specific patient characteristics and response to treatment.

Keywords: Hypertensive drugs, Type-2 Diabetes, Monotherapy and combination, Prescription pattern.

Copyright @ 2020: This is an open-access article distributed under the terms of the Creative Commons Attribution license which permits unrestricted use, distribution, and reproduction in any medium for non-commercial use (NonCommercial, or CC-BY-NC) provided the original author and source are credited.

\section{INTRODUCTION}

People with both diabetes and hypertension have approximately twice the risk of cardiovascular disease as nondiabetic people with hypertension. Hypertensive diabetic patients are also at increased risk for diabetes-specific complications including retinopathy and nephropathy. Prescription pattern is one of the indicators of the current situation of a specific patient community or group. Hypertension is the most common modifiable risk factor for cardiovascular diseases (CVD), stroke and renal failure [1]. It is estimated that more than one billion adults are hypertensive worldwide and this figure is projected to increase to 1.56 billion by the year 2025 , which is an increase of $60 \%$ from 2000. Cardiovascular diseases and Hypertension are accounting for loss of $4 \%$ gross domestic product for low and middle income countries annually which is amounting 500 billion USD [2]. Clinical evidence suggests that lowering blood pressure (BP) with antihypertensive drugs reduces the risk of myocardial infarction, stroke, heart failure, revascularization procedures and end-stage renal diseases in hypertensive patients [3]. Diabetes mellitus is a leading cause of death and disability worldwide [4, 5]. Its global prevalence was about $8 \%$ in 2011 and is predicted to rise to $10 \%$ by 2030 [6]. Nearly $80 \%$ of people with diabetes live in low- and middle-income countries. In 2011, China was home to the largest 
number of adults with diabetes (i.e. 90.0 million, or $9 \%$ of the population), followed by India ( 61.3 million, or $8 \%$ of the population) and Bangladesh (8.4 million, or $10 \%$ of the population) [6]. Diabetes and hypertension are closely related diseases. Hypertension affects about $20-60 \%$ of patients with type-2 diabetes [7]. Serious cardiovascular events are more than twice likely in patients with diabetes and hypertension than either disease alone [8]. The benefits of tight blood pressure (BP) control in patients with diabetes exceed the benefits of tight glycaemic control and extend to the prevention of both macro-vascular and micro-vascular complications [9]. The indicators of prescribing practices measure the performance of health care providers in several key dimensions related to the appropriate use of drugs. The indicators are based on the practices observed in a sample of clinical encounters taking place at outpatient health facilities for the treatment of acute or chronic illness. These encounters can be observed retrospectively, from data recorded in historical medical records, or they can be observed prospectively, from a group of patients attending the clinic on the day the data are collected. For secondary analysis of specific diagnoses or drugs the average number of drugs per encounter, percentage of drugs prescribed by generic name, percentage of encounters with an injection prescribed and percentage of drugs prescribed from essential drugs list or formulary should be considered. Before starting the intervention we have studied about the concept of essential medicine. The Alma-Ata declaration during the International Conference on Primary Health Care in 1978 reaffirms that health is a fundamental human right and the attainment of the highest possible level of health is a most important worldwide social goal [10]. The Alma Ata declaration has outlined the eight essential components of primary health care and provision of essential medicines is one of them [10]. Essential medicines are those that satisfy the priority health care needs of the population [11]. Essential medicines are selected with due regard to disease prevalence and public health relevance, evidence of clinical efficacy and safety, and comparative costs and costeffectiveness. Essential medicines are intended to be available within the context of functioning health systems at all times in adequate amounts, in the appropriate dosage forms, with assured quality, and at a price the individual and the community can afford [11]. The WHO has published a model list of essential medicines. Each country is encouraged to prepare their own lists taking into consideration local priorities. Over 150 countries have published an official essential medicines list. The essential medicines list enables health authorities, especially in developing countries, to optimize pharmaceutical resources. The WHO List contains a core list and a complementary list. The core list presents a list of minimum medicine needs for a basic health care system, listing the most efficacious, safe and cost-effective medicines for priority conditions. Priority conditions are selected on the basis of current and estimated future public health relevance, and potential for safe and cost-effective treatment. The complementary list presents essential medicines for priority diseases, for which specialized diagnostic or monitoring facilities are needed. In case of doubt medicines may also be listed as complementary on the basis of higher costs or less attractive cost-effectiveness in a variety of settings. The list is important because, it forms the basis of national drugs policy in more than 155 countries, both in the developed and developing world. Many governments refer to WHO recommendations when making decisions on health spending. There is a drug policy on essential medicines in Bangladesh also. Essential drugs are the foundation for public health program aimed at reducing morbidity and mortality in the developing world like Bangladesh, and pharmaceutical expenditure can account for a high proportion of the total health expenditure of the country. The Ministry of Health has finally approved a new list of essential drugs after 25 years, aiming to make key medicines available and affordable throughout the country. Initial list of essential drugs contains around items of which 117 are price controlled. Under the new list the number has been expanded to 209, reflecting advances in medical treatment during the last two decades [12]. It is a well-known fact that HTN being a chronic disease require life-long treatment and pharmacotherapy for the same, effectively controls blood pressure, when given appropriately. Rational prescription patterns are defined as patients receiving medications according to their medical condition, in doses that meet their requirements, for an adequate period of time, and at affordable cost to them and the society. Appropriate prescribing has a positive implication on medication adherence and disease improvement [13]. Irrational prescription pattern (IPP) occurs when the antihypertensive drug is given at inappropriate dose, frequency, and duration. IPP is strongly associated with poor control of chronic diseases including HTN. Uncontrolled blood pressure (UBP) is an independent risk factor leading to enormous complications and mortalities secondary to HTN. Inappropriate provision of medications could also lead to extra expense incurred to the patient due to ineffective treatment and adverse drug reactions [14]. As a component of pharmacoepidemiological techniques, prescribing pattern surveys provide an unbiased picture of prescribing habits and help identify suboptimal prescribing patterns for further evaluation. Such kinds of analytical studies are the best design to compare drug utilization and prescription patterns with respect to outcome of treatment. Prescribing pattern surveys of chronic medication could be assumed as medication reconciliation (Medrec) if they can be carried out periodically. Study reviled that routine evaluation of prescription patterns resulted in a cost saving of more than USD307.4 million per year [15]. Rational use of a drug is the essence for the successful treatment of any disease. However, many clinicians practice their own prescribing pattern in treating 
hypertensive patients according to their clinical experience. Primary care physicians need to be empowered in appropriate and evidence-based management of hypertension. A review of these prescribing patterns and guideline-based use of antihypertensive medications can give better insights into the concept of personalized, yet cost-effective pharmacological management of hypertension.

\section{OBJECTIVES \\ General Objective}

- To assess the uses of monotherapy and combination of antihypertensive drugs for hypertensive patients with type- 2 diabetes.

\section{Specific Objective}

- To observe the types of combination of antihypertensive drugs for hypertensive patients with type-2 diabetes.

- To observe the drug groups usually used in monotherapy and in combination therapy.

\section{Methodology \& Materials}

This was an observational cross sectional study and it was conducted in Dhaka Medical College Hospital and BIRDEM Hospital during the period from July 2016 to June 2017. In total 140 diagnosed hypertensive patients with type 2 diabetes mellitus attending to the Endocrine Departments of Dhaka Medical College Hospital and BIRDEM Hospital completed the full tenure of the study were finalized as the study population. According to the inclusion criteria hypertensive patients with type 2 diabetes mellitus aged more than 18 years irrespective of sex were included in the study. On the other hand, according to the exclusion criteria of the study type 1 diabetes patients, patients with gestational diabetes mellitus, patients aged less than 18 years, patients with suspected secondary hypertension were excluded. The study was approved by the ethical committee of both the mentioned hospital. Before starting the main part of the intervention proper written consents were taken from all the participants. This study had done by collection of prescriptions by convenient non probable sampling technique from type 2 diabetic patients who presented with hypertension. Detailed history from each patient were recorded based on a questionnaire and analyzed. Research instruments were prescriptions written by the physicians and data collection sheet. The prescription were scanned and stored for further analysis. All relevant information were recorded on the basis of a prescription checklist. The data were analyzed manually. Descriptive analytic techniques involving percentage, mean etc. were applied. After data analysis, results were find out according to the objectives, study result were presented in the form of tables, charts and description of the key findings according to need. The collected data were also be entered and analyzed using statistical software SPSS version 16 .

\section{RESULT}

In this study, a total of 140 prescriptions containing antihypertensive drugs were collected from patients attending the endocrine out-patient department of Dhaka Medical College Hospital and BIRDEM General Hospital. The information and observations were analyzed from two source. Among 140 patients in DMCH and BIRDEM, most of the patients were belongs to the age group 46-60 years. In total 38 patients from DMC and 28 from BIRDEM, total 66 $(47.1 \%)$ number in that age group. Besides this, $38.6 \%$ from $18-45$ age group and $14.3 \%$ from age group $>60$ years. In total, 55(39.3\%) were male and 85(60.7\%) were female patients. In total $42(30 \%)$ came from rural area and $98(70 \%)$ came from urban areas. In this study, $28(20 \%)$ had no formal education, $46(32.9 \%)$ patients were in primary level, $49(35 \%)$ patients were in secondary level and $17(12.1 \%)$ were graduate and above. According to the monthly family income of the participants, out of 140 patients $44(31.4 \%)$ were belongs to low income group, $63(45 \%)$ patients were in medium income group and $33(23.6 \%)$ patients were belongs to high income group. In this study, out of 140 patients, $120(86 \%)$ had H/O hypertension for less than 10 years, $19(13 \%)$ patient had history of taking antihypertensive drugs for 10-20 years and 1 patient had $\mathrm{H} / \mathrm{O}$ hypertension for more than 20 years. In this study commonly used hypertensive drugs were ARBs (Angiotensin II Receptor Blockers), CCBs (Calcium Channel Blockers) Diuretics, Beta-Blockers and ACEIs (ACE inhibitors) and that were used in 31\%, 24\%, 19\%, $18 \%$ and $8 \%$ patients respectively. In total $66(47.1 \%)$ patients of this study taken single drug and 74 (52.9\%) patients taken combination drugs. In this study among 74 patients of combination therapy, $73 \%, 23 \%$ and $4 \%$ patients taken double, triple and quadruple combination of antihypertensive drugs respectively. On the other hand among total participants $(n=140)$ this ratio was $38.57 \%, \quad 12.14 \%$ and $2.14 \%$ respectively. As monotherapy among 66 patients of monotherapy, ARBs, CCBs, ACEIs, Beta Blockers, and diuretics were used in $35 \%, 23 \%, 20 \%, 16 \%$ and $6 \%$ patients respectively. Among the total participants $(n=140)$ this ratio was $16.43 \%, 10.71 \%, 9.29 \%, 7.86 \%$ and $2.86 \%$ respectively. In DMCH, ARB + Diuretics (8) and ARB $+\mathrm{CCB}$ (8) were most commonly used combinations. On the other hand, in BIRDEM, ARB + Diuretics (13) were most commonly used combinations and then $\mathrm{B}$. Blocker + CCB (11) were most commonly used. In this study total number of prescribed antihypertensive drugs 732 and the mean $( \pm \mathrm{SD})$ number of antihypertensive drugs was $5.22 \pm 2.4$. In $11.40 \%$ cases injectable drugs were used whereas in $88.80 \%$ cases no injectable drug had been used. In this study in most of the cases $(71 \%)$ drugs from Essential Drug List of Bangladesh had been used. 
Table-1: Socio-demographic characteristics of participants $(\mathrm{N}=140)$

\begin{tabular}{|l|l|l|}
\hline Characteristics & n & $\%$ \\
\hline Age in years & 54 & $38.57 \%$ \\
\hline $18-45$ & 66 & $47.14 \%$ \\
\hline $46-60$ & 20 & $14.29 \%$ \\
\hline$>60$ & 55 & $39.29 \%$ \\
\hline Sex & 85 & $60.71 \%$ \\
\hline Male & 42 & $30.00 \%$ \\
\hline Female & 98 & $70.00 \%$ \\
\hline Residence & \multicolumn{3}{|l|}{} \\
\hline Rural & 28 & $20.00 \%$ \\
\hline Urban & 46 & $32.86 \%$ \\
\hline Level of education & 49 & $35.00 \%$ \\
\hline Non-formal education & 17 & $12.14 \%$ \\
\hline Primary level & 44 & $31.43 \%$ \\
\hline SSC/HSC level & 63 & $45.00 \%$ \\
\hline Graduate level & 33 & $23.57 \%$ \\
\hline Monthly family income in BDT \\
\hline Low (<10,000)
\end{tabular}

Table-2: Duration of hypertension of participants

\begin{tabular}{|l|l|l|}
\multicolumn{1}{|c}{$\mathbf{N = 1 4 0 )}$} \\
\hline Duration & $\mathbf{n}$ & $\mathbf{\%}$ \\
\hline <10 Years & 120 & $85.71 \%$ \\
\hline 10-20 Years & 19 & $13.57 \%$ \\
\hline$>20$ Years & 1 & $0.71 \%$ \\
\hline
\end{tabular}

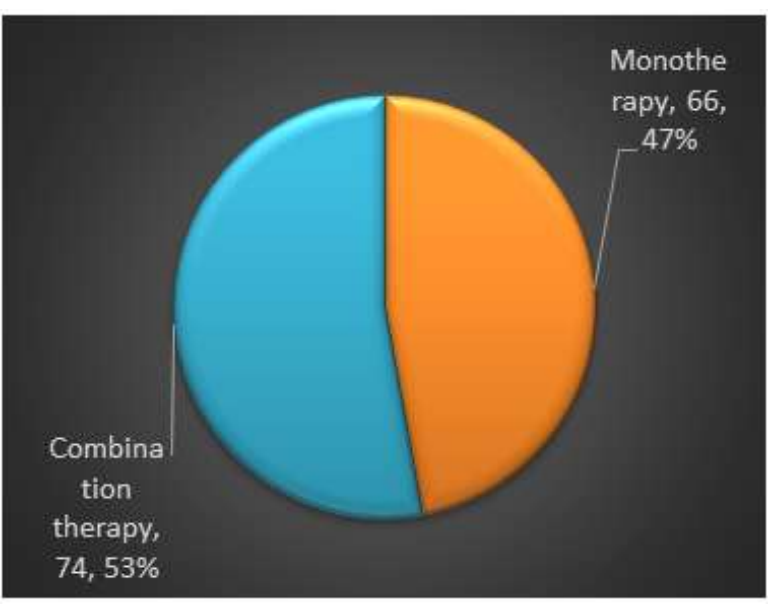

Fig-1: Types of antihypertensive therapy $(\mathrm{N}=\mathbf{1 4 0})$

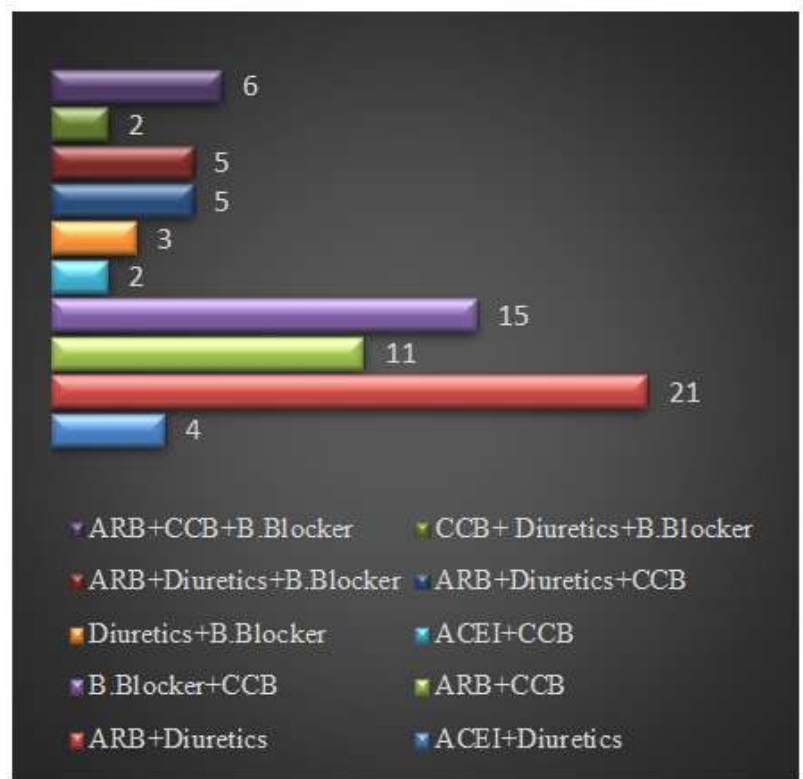

Fig-2: Common antihypertensive drug combinations $(\mathrm{N}=140)$

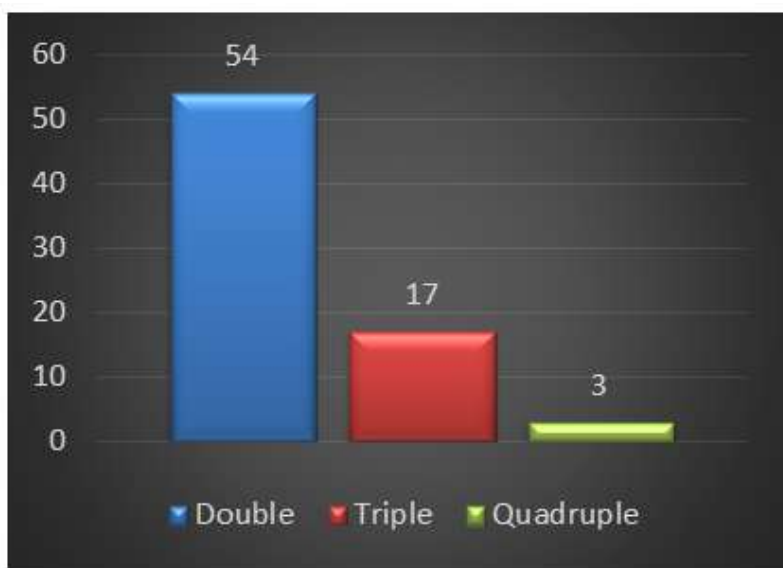

Fig-3: Types of combination of antihypertensive drugs $(\mathrm{N}=74)$

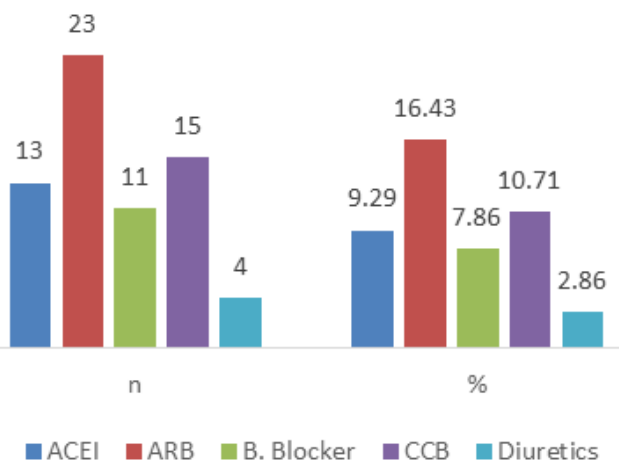

Fig-4: Drug groups used as monotherapy $(\mathrm{N}=140)$ 


\section{DISCUSSION}

The aim of this study was to assess the uses of monotherapy and combination of antihypertensive drugs for hypertensive patients with type-2 diabetes. The study was performed based on the data of prescriptions containing antihypertensive drugs with some parameters which elaborated here. In relation to the age distribution, majority of the patients are in the age group 46-60 years (47.1\%) in both sexes in DMCH and BIRDEM, which was similar to a study done at India [1]. Another Indian study showed similar age distribution $[2,16]$. This shows that advanced ages are not only the risk factor of hypertension; sedentary life style, food habits and stress also plays an important role leading to it [2]. Out of total 140 prescription analyzed, 70 from DMCH and 70 from BIRDEM, male was $48.6 \%, 39.3 \%$ and female was $51.4 \%, 60.7 \%$ in $\mathrm{DMCH}$ and BIRDEM respectively. In a large scale study done at OPD, BIRDEM [17] showed, 73\% outdoor diabetic patient were female. Higher female prevalence should be clarified by further study. The study showed that, 74 $(52.9 \%)$ patients were receiving combination drugs and $66(47.1 \%)$ patients were taking single drug. In DMCH, out of 70 patients, $38(54.3 \%)$ patients were taking single drug and $32(45.7 \%)$ patients were taking combination drugs whereas in BIRDEM, 28 (40\%) patients were taking single drug and $42(60 \%)$ patient taking combination drugs. So, majority of patients were receiving combination drug therapy. It was consistent with other studies $[18,19]$. Use of multiple drugs in combinations is being increasingly recognized as critical to control hypertension in patients with diabetes. Several large clinical trials demonstrated that most patients with hypertension could achieve and sustain adequate blood pressure control only with the use of multiple antihypertensive drugs [18]. Large proportion of treated patients $(52.9 \%)$ were being prescribed multidrug regimens. In addition, it was intensified with increasing age, duration of diabetes, duration of hypertension or if complications or comorbidities were present, this was in consistency with treatment pattern of the evidence based guidelines. ACEI/ARB were mainly used in this study either alone or in combination. It was consistent with other studies [5]. Regarding monotherapy, ARB and ACEI were the most commonly prescribed antihypertensive drugs followed by CCB, B. Blockers and diuretics. Several other study showed similar results $[18,20]$. ACEIs have shown a specifically beneficial effect in microvascular disease in kidney. It is mainly due to decreasing capillary perfusion, reducing transcapillary leakage of albumin, and in long run decrease damage to both capillaries and arteries [21]. In addition to ACEIs, ARBs have shown benefits not only in nephropathy, heart failure protection but also in reducing incidence of hyperkalemia and dry cough. The UKPDS showed the beneficial effects of the ACE inhibitor on diabetesrelated mortality and microvascular and cardiovascular complications in patients with type 2 diabetes [22]. Finally, the use of the ACE inhibitor ramipril in the heart outcomes prevention evaluation (HOPE) trial resulted in a reduction in all-cause and cardiovascular mortality as well as cardiovascular events, including myocardial infarction and stroke [23]. It has been described that initial monotherapy ACE inhibitors may be superior to dihydro-pyridine $\mathrm{CCB}$ in reducing cardiovascular events [24]. In the present study, calcium channel blockers were used in $n=56$ patients either in combination or as monotherapy. JNC 8 also recommends calcium channel blockers as first line drug in diabetic hypertensive patient [25]. Angiotensin receptor blocker with diuretics was the most commonly used dual drug combination strategy in our study. It was followed by combination of beta blocker with calcium channel blocker, calcium channel blocker with angiotensin receptor blocker, ACE inhibitor with diuretic and ACE inhibitor with beta blocker. Combination utilization pattern has been shown in Figure-2. Combination of ARB plus B. blocker plus CCB was most commonly used in patients on triple drug combination followed by combination of $\mathrm{ARB}$, diuretic with $\mathrm{CCB}$ and combinations of $\mathrm{ARB}$ plus $\mathrm{B}$. blocker plus diuretics. Next common triple drug combination is B. blocker plus CCB plus diuretics. The use of ARB and ACEI among diabetic hypertensive patients was in accordance with the JNC-8.As per JNC8 [25] in general nonblack population with diabetes initial antihypertensive therapy should include a thiazide type diuretics/ACEI/ARB/CCB and in black patient $\mathrm{CCB} /$ diuretics. They do not recommended to use B. blocker as monotherapy and in the present study, they were used more commonly than diuretics. Diuretics were least used as monotherapy in the present study although they are among the first line drugs recommended by JNC-8 for diabetic hypertensive. Regarding complications neuropathy were most common complication followed by IHD, nephropathy, retinopathy and stroke. It was consistent with previous study done [26]. Average no of drugs per prescription in DMCH were 4.74 and in BIRDEM were 5.42. Similar type of study done at India, it were 2.6 [27]. No drugs were prescribed in generic name, in total $16(11.4 \%)$ prescription had injectable drugs and 124 (88.4\%) had no injectable drugs. Majority of drugs in both hospitals were prescribed from Essential Drug List of Bangladesh. These findings are consistent with previous study [27].

\section{Limitations OF THE STUDY}

This was a single centered study with a small sized sample. The time period of data collection was not sufficient. The study was done in only two tertiary hospitals. So variation of prescribing patterns in different hospitals could not be evaluated. So the findings of this study may not reflect the exact scenario of the whole country. 


\section{CONCLUSION AND}

\section{RECOMMENDATIONS}

Besides monotherapies combination therapies of antihypertensive drugs are used on a big ratio of hypertensive patients with type- 2 diabetes. Moreover, there was higher use of B. blockers and less use of diuretics in our study. Still there is room for better control of hypertension and optimization of antihypertensive therapy. In spite of these data and published guidelines, inconsistencies exist towards treatment approach, because of which physicians sometimes have to individualize the therapy, based on specific patient characteristics and response to treatment. In developing countries like Bangladesh, more systematic studies are required on the evaluation of prescribing patterns and guideline based antihypertensive medications' use, which can be tailored to suit the patients' requirements.

\section{REFERENCES}

1. Go AS, Mozaffarian D, Roger VL. American Heart Association Statistics Committee and Stroke Statistics Subcommittee, et al. Heart disease and stroke statistics - 2014 update: A report from the American Heart Association. Circulation. 2013; 129:e28-292.

2. World Health Organization (WHO). A global brief on hypertension. Available at: http://www.who.int/ cardiovascular_diseases/publications/global_brief_ hypertension/en/. Accessed on: 02 Jan 2015.

3. James PA, Oparil S, Carter BL. Eighth Joint National Committee (JNC 8) Members, et al. 2014 evidence-based guideline for the management of high blood pressure in adults: report from the panel members appointed to the Eighth Joint National Committee (JNC 8), Supplemental Content. JAMA. 2014;311:507-20.

4. Lozano R, Naghavi M, Foreman K, Lim S, Shibuya K, Aboyans V, Abraham J, Adair T, Aggarwal R, Ahn SY, AlMazroa MA. Global and regional mortality from 235 causes of death for 20 age groups in 1990 and 2010: a systematic analysis for the Global Burden of Disease Study 2010. The lancet. 2012 Dec 15;380(9859):2095-128.

5. Murray CJ, Vos T, Lozano R, Naghavi M, Flaxman AD, Michaud C, Ezzati M, Shibuya K, Salomon JA, Abdalla S, Aboyans V. Disabilityadjusted life years (DALYs) for 291 diseases and injuries in 21 regions, 1990-2010: a systematic analysis for the Global Burden of Disease Study 2010. The lancet. 2012 Dec 15;380(9859):2197223.

6. International Diabetes Federation (IDF) [Internet]. Country estimates table 2011. IDF diabetes atlas. 6th ed. 2012. Available from: http://www.idf.org/sites/default/files/EN_6E_Atlas _Full_0.pdf [accessed 7 June 2013].
7. Arauz-Pacheco C. The treatment of hypertension in adult patients with diabetes. Diabetes Care. 2002 January; 25(1):134-147.

8. UK Prospective Diabetes Study Group. Tight blood pressure control and risk of macrovascular and microvascular complications in type 2 diabetes: UKPDS 38. Bmj. 1998 Sep 12;317(7160):703-13.

9. Chin MH, Su AW, Jin L, Nerney MP. Variations in the care of elderly persons with diabetes among endocrinologists, general internists, and geriatricians. J Gerontol A Biol Sci Med Sci. 2000; M601-6.

10. Declaration of Alma Ata. 1978. Available from:http://www.who.int/hpr/NPH/docs/declaratio n_almaata.pdf [last accessed on 2009 Oct 10]

11. WHO. Essential medicines. 2017. Available from:http://www.who. int/medicines/ services/ essmedicines_def/en /[Accessed: 12/03/2017]

12. Bangladesh Gazette. LIST OF ESSENTIAL DRUGS. 2008. Available from: http://www.dgda.gov.bd/index.php/2013-03-3105-16-29/guidance-documents/10-list-of-essentialdrugs?path $=$ [Accessed:12/03/2017]

13. Shrank WH, Hoang T, Ettner SL, Glassman PA, Nair K, DeLapp D, Dirstine J, Avorn J, Asch SM. The implications of choice: prescribing generic or preferred pharmaceuticals improves medication adherence for chronic conditions. Archives of internal medicine. 2006 Feb 13;166(3):332-7.

14. Iyalomhe GB, Omogbai EK, Iyalomhe OO. Longterm electrolyte effects during initiation of antihypertensive therapy with amlodipine or hydrochlorothiazide in diabetic Nigerians. Am J Med Sci Med. 2013;1(3):31-37

15. Chiatti C, Bustacchini S, Furneri G, Mantovani L, Cristiani M, Misuraca C, Lattanzio F. The economic burden of inappropriate drug prescribing, lack of adherence and compliance, adverse drug events in older people. Drug safety. 2012 Jan 1;35(1):73-87.

16. Hage FG, Mansur SJ, Xing D, Oparil S. Hypertension in women. Kidney international supplements. 2013 Dec 1;3(4):352-6.

17. Karim A, Khanom P, Nahar M. Prescribing pattern of medicines at outpatient department: Experience in BIRDEM General Hospital. Biennial meeting DASG (Diabetes in Asia Study Group) Abstract. 2016; P/1/010:58.

18. Konwar MA, Paul PK, Das SW. Prescribing pattern of antihypertensive drugs in essential hypertension in medicine out patients department in a tertiary care hospital. Asian Journal of Pharmaceutical and Clinical Research. 2014;7(2):142-4.

19. Dhanaraj E, Raval A, Yadav R, Bhansali A, Tiwari P. Prescription pattern of antihypertensive agents in T2DM patients visiting tertiary care centre in North India. International journal of hypertension. 2012 Dec 18;2012. 
20. Patel Nagar D, Kumar H. To study the preferred antihypertensive drugs in patients suffering from diabetes mellitus at a tertiary care hospital of Uttarakhand with an emphasis on compelling indications. International Journal of Basic \& Clinical Pharmacology. 2016 Sep;5(5):2032.

21. Newby DE, Grubb NR, Bradbury A. Cardiovascular diseases. In: Walker RB, Colledge NR, Ralston HS, Penman ID. (eds.) Davidson's Principles and Practices of Medicine. $22^{\text {nd }}$ ed; Edinburgh: Elsevier: 2014:607-612.

22. UKPDS 38. Tight blood pressure control and risk of macrovascular and microvascular complications in Type 2 Diabetes: UK prospective diabetes study group. BMJ. 1998; 317(7160):703-13.

23. Dickstein K, Kjekshus J, OPTIMAAL Steering Committee, OPTIMAAL Study Group. Effects of losartan and captopril on mortality and morbidity in high-risk patients after acute myocardial infarction: the OPTIMAAL randomised trial. The Lancet. 2002 Sep 7;360(9335):752-60.
24. Nather A, Bee CS, Huak CY, Chew JL, Lin CB, Neo S, Sim EY. Epidemiology of diabetic foot problems and predictive factors for limb loss. Journal of Diabetes and its Complications. 2008 Mar 1;22(2):77-82.

25. James PA, Oparil S, Carter BL, Cushman WC, Dennison-Himmelfarb C, Handler J, Lackland DT, LeFevre ML, MacKenzie TD, Ogedegbe O, Smith SC. 2014 evidence-based guideline for the management of high blood pressure in adults: report from the panel members appointed to the Eighth Joint National Committee (JNC 8). Jama. 2014 Feb 5;311(5):507-20.

26. Aghili M, Shekar HS. Study of prescribing pattern of antihypertensive drugs in diabetes patients. Int $\mathrm{J}$ Res Pharm Sci, 2016; 6(2):1-4.

27. The WHO Essential Medicines and Health Products Information Portal .How to Investigate Drug Use in Health Facilities: Selected Drug Use Indicators. Available from: http://apps.who. int $/$ medicinedocs/ en/d/Js2289e/ 3.1.html. [Accessed:12/03/2017]. 